\title{
Cross Sectional Assessment of Knowledge, Attitude and Practice towards Hepatitis C among Adolescents in Quetta, Pakistan
}

Muhammad Hashim Mengal ${ }^{1}$, Farzeen Tanver ${ }^{2}$, Mohammad Azam ${ }^{3}$, Mohammad Alam Mengal ${ }^{4}$, Mohammad Aslam Mengal ${ }^{5}$, Mohammad Kamran Taj ${ }^{6}$

${ }^{1}$ Department of Public Health \& Epidemiology, Umea University, Sweden

2Ziauddin Medical University, Karachi, Pakistan

${ }^{3}$ Bolan Medical College, Surgery Dept, Quetta, Baluchistan, Pakistan

${ }^{4}$ CASVEB, Quetta, Baluchistan, Pakistan

${ }^{5}$ Jinnah Postgraduate Medical Centre (JPMC), Karachi, Pakistan

${ }^{6}$ CASVEB, Quetta, Baluchistan, Pakistan

"Corresponding author: Farzeen Tanver, Director of Post graduate Studies and Research, Associate Professor and HOD, Department of Periodontology, Ziauddin Medical University, Karachi, Pakistan, Tel: 9221358629379; E-mail: farzeen_tanwir@yahoo.com

Rec Date: Aug 28, 2014; Acc Date: Nov 7, 2014; Pub Date: Nov 12, 2014

Copyright: @ 2014 Mengal MH et al., This is an open-access article distributed under the terms of the Creative Commons Attribution License, which permits unrestricted use, distribution, and reproduction in any medium, provided the original author and source are credited

\begin{abstract}
Background: Hepatitis $\mathrm{C}$ infection is growing threat and major burden on public health, worldwide prevalence of hepatitis C is $3 \%$ (170 million infected people). Approximately 10 million people are infected in Pakistan and prevalence is expected to be higher in remote areas. The aim of this study is to assess knowledge, attitude and practice of adolescents towards hepatitis C in Quetta Pakistan.
\end{abstract}

Methods: A cross sectional descriptive study carried out from February 2013 till April 2013. Sample size of this study was 456 and method of sampling was four stage cluster sampling. Samples were randomly selected from 12 schools in urban and semi-urban parts of district Quetta. Equal number of participants were selected (228 Male and 228 Female) from urban and semi-urban settings. Close ended questionnaire was designed, checked and used to access knowledge, attitude and practice of the participants towards hepatitis $\mathrm{C}$ infection

Results: Response rate of this survey was $100 \%$ and mean number of "Yes" answers to knowledge, attitude and practice questions were $51 \%, 46 \%$ and $42 \%$ respectively. The respondent's in urban setting has two times (1.92 odds) higher knowledge, positive attitude and practice than semi-urban participants. Furthermore the respondent's in higher educational level has two times (1.7 odds) better knowledge, positive attitude and practice than lower educational level participants. Furthermore this study indicates to reveal some evidence of stigmatization being exhibited by participants in both setting. Higher level of school education (group III) and older age (group III) respondents in both setting has positive attitudes toward hepatitis $C$ than lower level of education (group I) and younger age (group I). In addition it is observed that adolescents by growing age and entering higher education group are getting more knowledge and positive attitude and practice about hepatitis $C$ disease and it's a positive trend.

Conclusions: This study observed that knowledge, positive attitudes and practices towards hepatitis $\mathrm{C}$ among adolescents was partial in both setting. There are some important gaps need to be strengthened especially in semiurban setting and female group of participants. The results of study indicate that there is lack of understanding about infection control and prevention of hepatitis $\mathrm{C}$ among study participants. Thus there is need of critical level of public awareness in district Quetta, especially among adolescents, to decrease burden of hepatitis C infection. Extensive health education campaigns about hepatitis $\mathrm{C}$ are beneficial for adolescents, particularly to residents of semi-urban and rural areas.

Keywords: HCV; Hepatitis C prevalence; Knowledge; Attitude; Practice; Adolescents; School age children; Quetta

\section{Introduction}

Hepatitis $\mathrm{C}$ disease is caused by hepatitis $\mathrm{C}$ virus in human. Acute hepatitis $\mathrm{C}$ infection is asymptomatic in nature and later it leads to chronic hepatitis [1]. The chronic hepatitis leads to scarring of liver (liver cirrhosis) and its major cause of morbidity and mortality [2]. Globally, 170 million people are infected by hepatitis $\mathrm{C}$ virus, estimated prevalence is $3 \%$ and annual incidence is $3-4$ million.
Approximately 250,000 to 300,000 people die every year due to hepatitis $\mathrm{C}$ infection worldwide. The country wise highest prevalence rate of hepatitis C is observed in Egypt, 10-20\% [3].

Hepatitis $\mathrm{C}$ infection is growing challenge for Pakistan. Estimated prevalence rate is $4.8 \%$ and about 10 million people are infected in Pakistan [4]. The mode of transmission of hepatitis $\mathrm{C}$ are believed to use of contaminated needles and instruments in medical practice, blood product transfusion, intravenous drug abuse, used barber blades, infected instruments for ear and nose piercing and poor personal hygiene [5]. 
Previous studies observed that in developed countries about 20-40\% intravenous drug abusers are infected by hepatitis $C$ virus in their $1^{\text {st }}$ year of practice. Rest of $90 \%$ get infected after five years of intravenous drug use [5]. The sexual mode of transmission is rare and casual contact (hugging, kissing and mother breast milk) and sharing food has no role of hepatitis $C$ transmission [6]. The mother to infant transmission has been observed, its $5 \%$ globally $[7,8]$. Hepatitis virus has five different types, A, B, C, D and E. Hepatitis A and E transmission route is faecal oral. Hepatitis $\mathrm{B}$ cause acute and chronic disease and effect primarily human liver. Hepatitis D needs hepatitis B virus for replication [9]. Acute clinical signs and symptoms of hepatitis infection are similar; for instance; fever, malaise, nausea, anorexia, abdominal discomfort, fatigue, dark urine, and jaundice [6]. There is no vaccine for hepatitis $C$ prevention but other four types of hepatitis can be prevented by vaccine [7]

Adolescence age is a period of challenges and opportunities for understanding oneself within social context. Adolescents or young people are $27 \%$ of world's population, aged 10-24 years. In Pakistan age group 10-29 is $40 \%$ of total population [4]. Young people at their transition period (childhood to adulthood) frequently experience psychological and social changes at puberty [10-14]. At this particular time of age children take up characteristics of adults and behave like them even though they are not adults yet. It is because of volatile nature of this stage, they are mostly prone to many risks including drug use, smoking, drinking, unprotected sex and many other practices [14].

The adolescent are at high risk of infection due to unsafe injections and unprotected sexual activities [11]. In consequence they are more exposed to infectious diseases, like hepatitis C. Hepatitis $C$ is also an issue of social injustice and it rears ugly head in most endemic countries. The myths and misinformation about hepatitis $\mathrm{C}$ mode of transmission have resulted in widespread discrimination against chronically infected individuals. Hepatitis C infected people are not allowed to work in food industry and forced to go through a routine pre employment hepatitis $\mathrm{C}$ screening in China. If anyone found hepatitis C positive, then can be expel from school or work $[7,13]$.

\section{Aim}

The aim of this study is to assess adolescent knowledge, attitude and practices about hepatitis $\mathrm{C}$ infection in urban and semi-urban areas of Quetta. This study used urban and semi urban gradient.

\section{Study Area}

This study was conducted in urban and semi-urban parts of district Quetta in Pakistan. Quetta is administratively divided in two towns. Estimated population is approximately 9,10,000. District Quetta has three major hospitals, several basic health units and doctor population ratio is $1 / 1520$. Major diseases in district Quetta are tuberculosis, hepatitis and diabetes mellitus, etc [15-23].

\section{Method and Material}

KAP study are surveys in population which collect information on what is known, believed and done in relation to particular topic. In this study hepatitis C related information was collected from participants. In KAP surveys, data are collected by interview questionnaire and then data analysed in qualitative or quantitative method [24-34].
In this study respondents were school going adolescents and fourstage cluster random sampling technique was used. Twelve selected schools approached and sample size was $n=456$. This survey was conducted from February 2013 till April 2013. Instrument of measurement was standardized close-ended questionnaire. A pilot study was conducted to check length of questionnaire and level of understanding of pupils to survey questionnaire. Previous KAP studies were consulted and World Health Organization recommended standards were followed. Questionnaire was divided into four sections; first section asked basic information and next three sections inquired knowledge, attitude and practice about hepatitis C. Pearson chi-square test was used to compare knowledge, attitude and practice about hepatitis $\mathrm{C}$ in urban and semi-urban adolescents. Likewise knowledge, attitude and practice were compared across education levels and gender. Level of significance for chi-square was set at 0.05 . Results with $\mathrm{p}$-value $<0.05$ were accepted as statistically significant. Informed consent was obtained from school principals, parents and participants. A questionnaire was anonymous and didn't require any identity and all data were kept confidential. The study was ethically approved by Department of epidemiology, Umea University in Sweden. Logistic regression analysis was done for interpretation of data. The analytical software, SPSS version 19 was used for analysis.

\section{Results}

A cross sectional study interviewed 456 adolescents in urban and semi-urban parts of district Quetta. The response rate of survey was $100 \%$ and age range was 10-18 years old adolescents. Equal numbers of participants were selected from both genders due to separate educational system. The respondents were divided into three age groups, group I was 10-12 years old, group II was 13-15 years old and group III was 16-18 years old adolescents. The highest percentage of respondents, $52 \%$, was in group II (13-15 years old). The lowest percentage, $11 \%$, were in age group I (10-12 years old) and p-value was $<0.008$. The Study participants were divided into three educational level groups. Group I were middle school students (Grade 6-8), group II were high school students (Grade 9-10) and group III were Intermediate students (Grade 11-12). The highest number of respondents, 40\%, was in group II (High school students).The lowest number of respondents, 29\%, was in group III (Intermediate students) and P-value was 0.675 . The difference is could be due to late starting of schooling because of social structure in Quetta. The respondents were divided into two categories by residence, urban and semi urban. The urban respondents were $54 \%$ and semi-urban were $46 \%,<0.001$. The difference is probably due to school enrolment of semi-urban residents in urban locality (Table 1).

\begin{tabular}{|l|l|l|l|}
\hline \multicolumn{1}{|l|}{ Demographic characteristics of respondents } \\
\hline & $\begin{array}{l}\text { Male } \\
\text { Number (\%) }\end{array}$ & $\begin{array}{l}\text { Female } \\
\text { Number (\%) }\end{array}$ & Total \\
\hline $10-12$ Years & $33(15)$ & $22(8)$ & 55 \\
\hline $13-15$ Years & $101(45)$ & $132(59)$ & 233 \\
\hline $16-18$ Years & $94(40)$ & $74(33)$ & 168 \\
\hline Middle & $76(33)$ & $69(30)$ & 145 \\
\hline High & $84(37)$ & $96(43)$ & 180 \\
\hline Intermediate & $68(30)$ & $63(27)$ & 131 \\
\hline
\end{tabular}


Citation: Mengal MH, Tanver F, Azam M, Mengal MA, Mengal MA, et al. (2014) Cross Sectional Assessment of Knowledge, Attitude and Practice towards Hepatitis C among Adolescents in Quetta, Pakistan. Dentistry 4: 263. doi:10.4172/2161-1122.1000263

Page 3 of 7

\begin{tabular}{|l|l|l|l|}
\hline Urban & $108(47)$ & $136(60)$ & 244 \\
\hline Semi-urban & $120(53)$ & $92(40)$ & 212 \\
\hline
\end{tabular}

were $68 \%$ and $26 \%$ respectively. Most of respondents knew about hepatitis $\mathrm{C}$, its viral causation, it effect primarily liver and it can cause cancer but on other hand just $38 \%$ knew it can affect adolescents. Surprisingly $64 \%$ believe that hepatitis C infected people are at risk to

Table1: Demographic characteristics of respondents by Age, education level and residence $(\mathrm{N}=456)$

\section{Respondent's knowledge towards hepatitis C}

Section II of questionnaire was about knowledge questions and inquired basic information, prevention and mode of transmission of hepatitis C among participants. Questions number 1-8 were about basic information and prevention of hepatitis C. Questions number 9-16 were about hepatitis $C$ mode of transmission. Each question response was scored "Yes" and "No". Mean number of "Yes" answers were $51 \%$. The range of highest and lowest responded "Yes" questions others and $57 \%$ think it could be caught through casual contact (holding hands). Majority think that hepatitis $\mathrm{C}$ has a vaccine in urban (52\%) and semi-urban (75\%) areas. Only $32 \%$ knew of shared tooth brush transmission. The contaminated blood, barber used infected blades, infected needle for tattooing and piercing knowledge was 58\% in educational group III, and it was $54 \%$ among educational group II and $48 \%$ in educational group III. Though $74 \%$ in urban setting knew that hepatitis $\mathrm{C}$ is not transmitted by water and food but majority, $70 \%$, were not aware of spread through contact open wounds/ cuts and mother to baby during pregnancy. The majority, $68 \%$ knew of unsterilized syringe transmission in urban setting (Table 2).

\begin{tabular}{|c|c|c|c|c|}
\hline \multicolumn{5}{|c|}{ Knowledge questions responded "Yes" } \\
\hline No & Knowledge Questions & Urban (\%) & Semi-urban (\%) & $\begin{array}{l}\text { P-value } \\
\text { X2 }\end{array}$ \\
\hline 1 & Ever heard about HCV? & 68.5 & 56.5 & 0.619 \\
\hline 2 & Is a viral disease? & 56 & 44.5 & 0.985 \\
\hline 3 & Not catch by contact? (hold hands) & 64.5 & 49.5 & 0.526 \\
\hline 4 & Infected are at risk to others? & 55 & 74 & 0.428 \\
\hline 5 & Vaccine not available? & 75 & 52.5 & 0.463 \\
\hline 6 & Affect adolescents? & 42.5 & 34 & 0.662 \\
\hline 7 & HCV cause cancer? & 68 & 61.5 & 0.573 \\
\hline 8 & Primarily effect human liver? & 66.5 & 60.5 & 0.323 \\
\hline 9 & Transmit by infected person shared tooth brush? & 38.5 & 25 & 0.340 \\
\hline 10 & Transmitting is not by water and food? & 30.5 & 20 & 0.750 \\
\hline 11 & $\begin{array}{l}\text { Transmit by } \\
\text { Contaminated blood? }\end{array}$ & 62 & 54 & 0.956 \\
\hline 12 & Transmit by unsterilized syringes? & 76 & 60 & 0.931 \\
\hline 13 & Transmit by barber used infected blades? & 61.5 & 45.5 & 0.878 \\
\hline 14 & Transmit by infected needle for tattooing and piercing? & 55.5 & 39.5 & 0.265 \\
\hline 15 & Transmit by contact to open wound/cuts? & 33.5 & 25.5 & 0.254 \\
\hline 16 & Transmit from mother to baby during pregnancy? & 35 & 27 & 0.650 \\
\hline
\end{tabular}

Table 2:Knowledge questions responded "Yes"

\section{Respondent's attitude towards hepatitis C}

Section II of questionnaire assessed attitude of respondents towards hepatitis C and each question response was scored "Yes" and "No". Mean number of "Yes" answers were 46\%. The range of highest and lowest responded "Yes" questions were $77 \%$ and $16 \%$ respectively. Most of respondents believe that hepatitis $\mathrm{C}$ is major health problem and incase they found infected then will go for further investigation in both settings. Only 35\% consider hepatitis C screening constructive and $63 \%$ respondents think it's positive to ask for screening during blood transfusion. About $16 \%$ were willing to greet in traditional way and kiss hepatitis $\mathrm{C}$ infected person. Furthermore 36\% respondents in urban setting were willing to use glass or cup of hepatitis $\mathrm{C}$ infected person. Though $65 \%$ respondents were agree to isolate hepatitis $\mathrm{C}$ infected person but about $42 \%$ are willing to visit hepatitis $\mathrm{C}$ infected relative, $44 \%$ willing to sit close to infected person and about $37 \%$ believe that hepatitis $\mathrm{C}$ affect ability of infected to visit others. The respondent's attitude wasn't fairly adequate towards HCV in both setting (Table 3 ). 
Citation: Mengal MH, Tanver F, Azam M, Mengal MA, Mengal MA, et al. (2014) Cross Sectional Assessment of Knowledge, Attitude and Practice towards Hepatitis C among Adolescents in Quetta, Pakistan. Dentistry 4: 263. doi:10.4172/2161-1122.1000263

Page 4 of 7

\begin{tabular}{|l|l|l|l|l|}
\hline \multicolumn{2}{|l|}{ Attitude questions responded "Yes" } & Urban (\%) & Semi-urban (\%) & $\begin{array}{l}\text { P-value } \\
\text { X2 }\end{array}$ \\
\hline No & Attitude Questions & 82 & 63 & 0.572 \\
\hline 1 & Consider hepatitis C a major health problem? & 43 & 26 & 0.324 \\
\hline 2 & Believe to go for screening? & 34 & 40 & 33 \\
\hline 3 & HCV +ve don't affect ability to visit others? & 51 & 36 & 32 \\
\hline 4 & Its safe to Visit HCV infected friend/relative? & 56.445 & 0.971 \\
\hline 5 & It's safe to sit close to hepatitis C infected person? & 21 & 10 & 0.880 \\
\hline 6 & It's safe to greet/kiss HCV infected person? & 45 & 28 & 0.935 \\
\hline 7 & It's safe to use cup/glass of HCV infected person? & 25 & 46 & 0.518 \\
\hline 8 & Think HCV infected person shouldn't isolate for prevention? & 85 & 40 & 0.408 \\
\hline 9 & Positive to ask for blood screening during transfusion? & 82 & 72 & 0.913 \\
\hline 10 & Think to go for further investigation if found HCV positive? & & 0.532 \\
\hline
\end{tabular}

Table 3: Attitude questions responded "Yes"

\section{Respondent's practice towards hepatitis C}

The section III of questionnaire assessed practice of adolescents towards hepatitis C. Each question response was scored "Yes" and "No". Mean number of "Yes" answers were $42 \%$. The range of highest and lowest responded "Yes" questions were 53\% and $18 \%$ respectively. Only $18 \%$ respondents were tested for hepatitis $\mathrm{C}$ and those to cover open wounds/ cuts were $53 \%$. About $42 \%$ respondents want to report needle/blade injuries to parents and teachers. About 37\% respondents ask for new syringes to medical staff. Around 52\% respondents ask for new blades to barbers and $47 \%$ of respondents ask for sterilize instruments to dentist. About $41 \%$ respondents ask for new needle for piercing and tattooing. Though $48 \%$ participants share others tooth brush and razors and $36 \%$ use others earrings and nail clippers (Table 4).

\begin{tabular}{|l|l|l|l|l|}
\hline \multicolumn{2}{|l|}{ Practice questions responded "Yes" } & Urban (\%) & Semi-urban (\%) \\
\hline No & Practice Questions & & P-value \\
\hline
\end{tabular}

Table 4: Practice questions responded "Yes"

\section{Logistic regression analysis}

Residence and educational level of respondents was positively associated with knowledge, attitude and practice (KAP). Compare to the semi-urban respondents (category II) and above the urban respondents (category I) had about two time's higher odds (1.92) for having better knowledge, positive attitude and practice towards hepatitis C. Compare to the educational level group 1 (youngest/ Middle School) and above the educational level group 3 (oldest/ Intermediate) had about two times higher odds (1.74) for having better knowledge, attitude and practice towards hepatitis $\mathrm{C}$. The $\mathrm{p}$-values were statistically significant in both categories $<0.005$. 
There was not a big difference of odds ratio among both sex in gender category and $\mathrm{p}$-value was above $>0.005$. Compare to the youngest age group I (10-12 years) and above the oldest age group III (16-18 years) had about 1.5 times higher odds (1.49) for having better knowledge, attitude and practice towards hepatitis C. The p-values was statistically significant in both categories $<0.005$. Details of logistic analysis are mentioned in Table 5 .

\begin{tabular}{|l|l|l|l|}
\hline \multicolumn{4}{|l|}{ Simple Logistic Regression Analysis } \\
\hline & Odds Ratio & Cl (95\%) & P-value \\
\hline $10-12$ Years & 1.0 & & \\
\hline $13-15$ Years & 0.43 & $0.27-0.70$ & 0.000 \\
\hline $16-18$ Years & 1.48 & $0.93-2.38$ & 0.000 \\
\hline Middle & 1.0 & & \\
\hline High & 0.45 & $0.29-0.71$ & 0.000 \\
\hline Intermediate & 1.73 & $1.07-2.83$ & 0.000 \\
\hline Urban & 1.92 & $1.32-2.79$ & 0.001 \\
\hline Semi-urban & 1.0 & & \\
\hline Male & 0.95 & $0.65-1.37$ & 0.779 \\
\hline Female & 1.0 & & \\
\hline
\end{tabular}

Table 5: Simple logistic regression analysis.

\section{Discussion}

The current study sought to evaluate knowledge, attitude and practice of school going adolescents towards hepatitis C.

\section{Knowledge}

Knowledge is produced by interaction with own environment where persons themselves build their understanding of world through experience. Human knowledge comes generally with communication processes and knowledge plays key role in prevention. I didn't found any available literature to support claim of geographical location influences on adolescent's level of knowledge of hepatitis $\mathrm{C}$ in district Quetta. A cross-sectional study conducted in Australia to assess secondary school student's level of knowledge about sexually transmitted infections in rural and urban localities, it was found that rural students were more knowledgeable about issues of sexually transmitted infections compared to their urban peers. A survey of rural Canadian student's sexually transmitted diseases knowledge discovered high levels of knowledge among both rural and urban students in Canada. Another KAP study was conducted in United States of America to determine adolescent's level of HIV knowledge in low risk rural areas and high risk urban areas and study observed that rural students had better knowledge of HIV and risk reduction strategies than their urban counterparts $[18,19]$. Above mentioned knowledge surveys observed opposite findings compare to this study and it's could be because of context and social structure of the society.

\section{Attitude}

Attitude is favourable or unfavourable reaction to objects, people, situations or other aspects of world. The cognition aspect of an individual to mean a person's knowledge of something, affective component represents an individual's feelings. The way people act towards situation and an individual motivation to make changes. Social psychologists considered attitude a cognition, affection and behaviour factor. The comprehensive attitudes are more stable and usually held by owners and as result it's very hard if not impossible to be influenced when compared to unspecific attitudes [20].

An individual behaviour can be predicted by using strength and consistency of their attitude. Thus any intervention that is aimed at changing behaviour of an individual must initially have enough information about his or her attitudes and later employ methods which will help for changing attitudes. Knowledge does not necessarily influence an individual attitude; people may be knowledgeable about particular risk behaviour but still practice it. A study concerning acquisition of HIV confirmed adolescents may continue to engage in behaviours that enlarged their risk of disease acquisition in spite of knowledge of the risk [19].

\section{Practice}

Individuals in society practice differently in own context. Adolescent think they are free and growing, its age of struggle for self identity. In this period of life tattooing and piercing is fashion and adolescents are highly motivated to practice these kind of fashion because they usually not receive much criticisms from society. Psychologist identified that adolescents are highly exposed to risk taking behaviour and several studies shown that male's adolescents are more risky than female [11].

Thus adolescent's efforts are not enough to prevent them from diseases. They have knowledge but underestimate risk of getting dangerous diseases. There is no publish literature on efforts made by adolescents to prevent themselves from contracting hepatitis $\mathrm{C}$ in district Quetta but studies gave divergent results in other parts of the world.

\section{Theory of reasoned action}

The theory of Reasoned Action was developed by Martin Fishbein and Icek Ajzen as upgrading over Information Integration theory. Firstly, reasoned actions added another element in process of persuasion, behavioural intention rather than attempt to guess attitudes. Theory is about behaviour but it admits situations which limit influence of attitude on behaviour. Theory predicts behavioural intentions and compromise between stopping predicting attitude and behaviour. Secondly, theory of reasoned action uses two elements, attitudes and norms to predict behavioural intention. Thus whenever our attitudes lead us to do one thing but relevant norms suggest that we should do something else. An individual belief is a particular behaviour that leads to a specific outcome and evaluates outcome, and then consequently forms an attitude towards the behavior [19,21].

Result of this study observed partial knowledge, attitude and practice towards hepatitis $\mathrm{C}$. The range of highest and lowest responded "Yes" to knowledge questions were $68 \%$ and $26 \%$ respectively. Mean number of "Yes" answers was 51\%, indicating low level of knowledge towards hepatitis $\mathrm{C}$ among respondents in both settings. Basic knowledge about hepatitis $\mathrm{C}$ and mode of transmission is essential for adolescent's prevention. The prevalence of hepatitis $\mathrm{C}$ is $4 \%$ in Pakistan with high morbidity and mortality [4]. Both gender respondents in urban and semi-urban knew basic information about hepatitis C but some differences observed. Overall semi-urban 
respondents knew less than urban and its might be due to quality of education, social structure and socioeconomic status of families. This study observed difference on gender basis; female exhibited higher knowledge than male and its might be due to curiosity to know about health issues, services and dangers. Fewer respondents (male and semi-urban) knew that mode of transmission is infected instrument for tattooing, piercing, barber blades, contact open wounds and use of share tooth brush. Epidemiological study was conducted in Indian village about outbreak of viral hepatitis and outbreak was linked to use of un-sterilized needles, reused blades and syringes [28]. This study discloses some evidence of stigmatization being exhibited by urban and semi-urban adolescents towards infected persons. Respondents in urban schools knew more than semi-urban and intermediate level participants knew more than middle level. The lack of respondent's knowledge towards hepatitis $\mathrm{C}$ is due to less exposure and discussion about hepatitis. Interaction with school principals and teaching staff revealed that nothing much about hepatitis $\mathrm{C}$ information is part of curriculum and occasional visits by health professionals mostly target Tuberculosis, malaria and polio awareness. This study authenticates a similar knowledge, attitude and practice study among high school respondents on reproductive health, urban respondents were more knowledgeable and better practice than rural respondents [29]. Crosssectional studies conducted in Australia and Ghana to assess secondary school student's level of knowledge about sexually transmitted infections and hepatitis B disease in rural and urban areas also found that urban respondents has better knowledge about infection and prevention than rural respondents $[12,30]$.

In section II of questionnaire, major proportion of respondents considers hepatitis $\mathrm{C}$ a major health issue and consider it constructive to go for further investigation incase found hepatitis $\mathrm{C}$ infected but minor proportion ever thought about screening and 63\% think it's positive to ask for screening during blood transfusion. Around 37\% respondents probably are direct risk of infection because of negative attitude. Female respondent's attitude towards hepatitis C infected found negative than male. The stigma observed in semi-urban respondent's (both gender) because less number of respondents are willing to sit close to hepatitis $\mathrm{C}$ infected person. Furthermore in both settings male is less willing to greet traditionally and kiss to infected person and moreover less willing to use hepatitis $C$ infected person's cup or glass. Theory of reasoned action forms the theoretical bases for this study means a person holds a belief that a particular behavior leads to a particular outcome and evaluates the outcome and consequently forms an attitude towards the behavior [19]. Semi-urban respondents want to isolate infected individual and this attitude is mark of stigmatization to infected person. Results validate assertion by Parker \& Angleton; stigmatization of diseases regularly marks beginning of rejection of potential personal risk because an important factor for behavioral change between adolescents at risk of disease is to have sense of humor for those who are infected [31]. Higher level of school and older age respondents in both setting has positive attitudes toward hepatitis $\mathrm{C}$ than lower level. Its positive trend that by getting older and entering in higher education level changes attitude more positive.

Concerning practice questions, only $18 \%$ were tested for hepatitis C, $48 \%$ share others tooth brush and razors and respondent's practice wasn't fairly adequate towards hepatitis $\mathrm{C}$ in both settings. Two main factors that influence behavior change are attitudes and social norms and lead to development of intention and ultimately implementation of intention into practice $[19,21]$. KAP study about hepatitis C in adults conducted in Hazara region of Pakistan, assessed knowledge, attitude and practice about hepatitis $\mathrm{C}$ in general population observed similar results [32].

Hepatitis $\mathrm{C}$ has no preventive vaccine yet thus following steps are important for prevention. Primary prevention is to avoid unnecessary and unsafe injection practice. Furthermore shouldn't handle unsafe blood products, sharps waste collection and disposal. In addition avoid sharing of injection syringes, unprotected sex with hepatitis C-infected people, sharing tooth brush and shaving razor. Be careful during tattooing, piercings and acupuncture procedure by contaminated equipment. Secondary and tertiary prevention is education and counseling. Moreover immunize for hepatitis A and B vaccine to prevent from co-infection. Finally appropriate medical management with antiviral therapy and regular monitoring is necessary for diagnosis in early stage $[15,16]$.

\section{Treatment}

There are six genotypes of hepatitis $C$ virus and each reaction is different to treatment. Therefore careful screening is necessary before starting treatment to determine most appropriate approach for patient. The initial treatment is antiviral therapy, interferon and ribavirin. When liver has been severely damaged then liver transplantation is another option. It replaces damaged liver with healthy liver of donor. Mostly donors are deceased individuals and small percentage is living donors who donate a portion of their liver to needy. Liver transplant is not an ultimate cure and antiviral medications are mandatory after surgery due to recurrence issue $[15,17]$.

\section{Strengths and limitations}

Strengths of this study were adolescents. In Pakistan age group $10-29$ is $40 \%$ of total population [4]. This study was low cost, easy to perform and explored knowledge, attitude and practice of adolescents towards hepatitis C. Participants were equally selected because of separate schooling system for both genders.

Limitations were restriction to school going adolescents and cross sectional design. In cross sectional design it's difficult to draw any conclusion on causation. The cross sectional descriptive survey is related with existing relationships and it determine nature of current conditions, practices and attitudes. Cross sectional descriptive design has advantage of eliciting responses from a wide range of people. It involves asking same set of questions to huge number of persons through mails, telephone, by hand on basis of data gathered at a point in time [24]. It suit researcher while describe some aspects of population through selecting unbiased samples of individuals who are asked to fill up questionnaire, interview and test. Disadvantages of descriptive design are errors and inadequacy of a survey. Close ended questionnaire may miss some informative results and close ended questionnaire can't produce most informative results and in some extent effects translation [25-27].

Moreover time and economical issue didn't let to adopt qualitative approach. This study conducted in one city so it's not representative of entire province and country.

\section{Conclusion}

Knowledge, attitudes and practice about hepatitis C among adolescents was partial. Results of this study indicate lack of understanding about basics of infection control and prevention of 
Citation: Mengal MH, Tanver F, Azam M, Mengal MA, Mengal MA, et al. (2014) Cross Sectional Assessment of Knowledge, Attitude and Practice towards Hepatitis C among Adolescents in Quetta, Pakistan. Dentistry 4: 263. doi:10.4172/2161-1122.1000263

Page 7 of 7

hepatitis C transmission. Thus critical level of public awareness, especially among adolescents is essential to decrease burden of hepatitis $\mathrm{C}$ infection.

\section{Recommendations}

Extensive health education campaigns toward hepatitis $\mathrm{C}$ are necessary for adolescents and especially to residents of semi-urban and rural areas. Preventive measures should be taken by administration of schools in form of running awareness programs and government should address hepatitis $\mathrm{C}$ issue comprehensively by enhancing surveillance, prevention, care, and treatment.

\section{References}

1. Rizzetto M (1992) Viral hepatitis: introduction. In Oxford Textbook of Clinical Hepatology. Edited by McIntyre N, Benhamou JP, Bicher J, Rizzeto M, Rodes J. Oxford: Oxford Medical Publication 529.

2. Nogol Rahbin (2012) Clinical features of chronic HCV and advance liver disease. Karloniska Inst Sweden.

3. CDC (1998) center of disease control and prevention USA.

4. Ahmad N, Asgher M, Shafique M, Qureshi JA (2007) An evidence of high prevalence of Hepatitis C virus in Faisalabad, Pakistan. Saudi Med J 28: 390-395.

5. Afridi S, Naeem M, Hussain A, Kakar N, Babar ME, et al. (2009) Prevalence of hepatitis $\mathrm{C}$ virus (HCV) genotypes in Balochistan. Mol Biol Rep 36: 1511-1514.

6. Recommendations for prevention and control of hepatitis $\mathrm{C}$ virus (HCV) infection and HCV-related chronic disease. Centers for Disease Control and Prevention. MMWR Recomm Rep 1998; 47: 1-39.

7. World Health Organization (2011) Hepatitis C: Fact sheet No. $164^{\circ}$ Geneva: Switzerland.

8. Carroll ST, Riffenburgh RH, Roberts TA, Myhre EB (2002) Tattoos and body piercings as indicators of adolescent risk-taking behaviors. Pediatrics 109: 1021-1027.

9. Ramsay DB, Friedman M, Borum ML (2007) Does the race or gender of hepatitis $\mathrm{C}$ infected patients influence physicians' assessment of hepatitis A and hepatitis B serologic status? South Med J 100: 683-685.

10. Kahn J (2006) Factor Analysis in Counseling Psychology Research, Training, and Practice: Principles, Advances, and Applications. Couns Psychol. 34: 684-718.

11. Johnson LS, Rozmus C, Edmisson K (1999) Adolescent sexuality and sexually transmitted diseases: attitudes, beliefs, knowledge, and values. J Pediatr Nurs 14: 177-185.

12. Batholomew Chireh (2011) Knowledge, Attitude and Practices (KAP) concerning Hepatitis B among Adolescents in the Upper West Region of Ghana. Umea University, Sweden.

13. Puro V, Petrosillo N, Ippolito G (1995) Risk of hepatitis C seroconversion after occupational exposures in health care workers. Italian Study Group on Occupational Risk of HIV and Other Bloodborne Infections. AmJ Infect Control 23: 273-277.

14. Jessor R (1998) New perspectives on adolescents risk behavior Cambridge University press, Cambridge, UK.
15. Jawaid Ali (2008) Treatment and vaccination of HCV, present and future; Agha Khan Medical University Pakistan. J Ayub Med Coll Abbottabad 20: 129-133.

16. Recommendations for prevention and control of hepatitis $\mathrm{C}$ virus (HCV) infection and HCV-related chronic disease. Centers for Disease Control and Prevention. MMWR Recomm Rep 1998;47: 1-39

17. Jonas MM (2002) Children with hepatitis C. Hepatology 36: S173-178.

18. Bledsoe LK (2006) Smoking cessation: an application of theory of planned behavior to understanding progress through stages of change. Addict Behav 31: 1271-1276.

19. Sheppard BH, Hartwick J, Warshaw PR (1988) The theory of reasoned action: A meta-analysis of past research with recommendations for modifications and future research. Journal of Consumer Research 15: 325-343.

20. Fishbein M, Ajzen I (1975) Belief, intention and behavior: Introduction to theory and research: Reading mass: Addison-Wesley Publishing Company.

21. World Health Organization: Advocacy, communication and social mobilization for TB control: a guide to developing knowledge, attitude and practice surveys.

22. Good B: Medicine, rationality, and experience: an anthropological perspective. Cambridge: Cambridge Univ Pr; 1994.

23. Azhar S, Hassali MA, Ibrahim MI, Ahmad M, Masood I, et al. (2009) The role of pharmacists in developing countries: the current scenario in Pakistan. Hum Resour Health 7: 54.

24. Aday L, Cornelius L (2006) Designing and conducting health surveys: a comprehensive guide.

25. Gay LR, Airasian P (2006) Educational research: Competencies for analysis and application. Upper Saddle River, NJ: Merrill Prentice Hall.

26. Behling O, Law KS (2000) Translating questionnaires and other research instruments: Problems and solutions. California: Sage Publications, Inc.

27. Harkness JA, Schoua-Glusberg A (1998) Questionnaires in translation. ZUMA-Nachrichten Spezial 3: 87-127

28. Singh J, Bhatia R, Gandhi JC, Kaswekar AP, Khare S, et al. (1998) Outbreak of viral hepatitis $\mathrm{B}$ in a rural community in India linked to inadequately sterilized needles and syringes. Bull World Health Organ 76: 93-98.

29. Wright SM, Gabb RG, Ryan MM (1991) Reproductive health: knowledge, attitudes and needs of adolescents. Med J Aust 155: 325-328.

30. Wyn J (1994) Young women and sexually transmitted diseases: the issues for public health. Aust J Public Health 18: 32-39.

31. Parker R, Aggleton P (2003) HIV and AIDS-related stigma and discrimination: a conceptual framework and implications for action. Soc Sci Med 57: 13-24.

32. Jamil MS, Ali H, Shaheen R, Basit A (2010) Prevalence, knowledge and awareness of hepatitis $\mathrm{C}$ among residents of three Union Councils in Mansehra. J Ayub Med Coll Abbottabad 22: 192-196.

33. Murray CJ, Ortblad KF, Guinovart C, Lim SS, Wolock TM, et al. (2014) Global, regional, and national incidence and mortality for HIV, tuberculosis, and malaria during 1990-2013: a systematic analysis for the Global Burden of Disease Study 2013. Lancet 384: 1005-1070.

34. World Health Organization (2008) A guide to develop KAP surveys. 